Bartın Üniversitesi İktisadi ve İdari Bilimler Fakültesi Dergisi,

2020, Cilt 11, Sayı 22

Bartın University Journal of Faculty of Economics and Administrative Sciences, 2020, Volume 11, Issue 22

ISSN: 1309-954X / E-ISSN: 2148-2497

http://iibfdergi.bartin.edu.tr/

http://dergipark.gov.tr/bartiniibf

Araştırma Makalesi, Gönderim Tarihi: 21.09.2020; Kabul Tarihi: 27.10.2020

\title{
Petrol Fiyatları ile Ekonomik Büyüme İlişkisi: Türkiye Örneği
}

\author{
Doç. Dr. Ahmet KAMACI \\ Bartın Üniversitesi, İIBBF, İktisat Bölümü \\ akamaci@bartin.edu.tr, Orcid ID: 0000-0002-7858-6131
}

Süleyman GÖKTAŞ

Bartın Üniversitesi, Lisansüstü Eğitim Enstitüsü, İktisat ABD

suleymangoktas14@gmail.com, Orcid ID: 0000-0003-1674-3389

\section{Öz}

Üretimde önemli bir üretim maliyeti olan petrol fiyatları, ekonominin tüm sektörlerini etkilemektedir. Petrol fiyatlarındaki artış, maliyet enflasyonuna yol açacak, bu da üretimin azalmasına ve ekonomik büyümenin daralmasına neden olacaktır. Petrol fiyatlarında yaşanan dalgalanmalar, ekonomi üzerinde bir belirsizlik doğurmaktadır. $\mathrm{Bu}$ durum ise, yatırımları azaltarak istihdamın ve milli gelirin düşmesine neden olmaktadır. Bu çalışmanın amacı, Türkiye'de 2003:Q1-2019:Q4 dönemlerindeki çeyreklik verilerle petrol fiyatları ile ekonomik büyüme ilişkisini incelemektir. $\mathrm{Bu}$ doğrultuda eşbütünleşme ve nedensellik analizi yapılmıştır. Çalışmadan elde edilen bulgulara göre, ekonomik büyümeden petrol fiyatlarına doğru tek yönlü bir nedensellik tespit edilmiştir. Aynı zamanda, petrol fiyatları ile ekonomik büyüme arasında uzun dönemli eşbütünleşik bir ilişki bulunmuştur.

Anahtar Kelimeler: Petrol, petrol fiyatları, ekonomik büyüme

JEL Sınıflandırması: Q43, F43, Q32.

\section{Oil Prices and Economic Growth: The Case of Turkey}

\begin{abstract}
Oil prices, which are an important production cost in production, affect all sectors of the economy. The increase in oil prices will lead to cost inflation, which will decrease production and cause a contraction in economic growth. Fluctuations in oil prices cause uncertainty over the economy. This situation decreases the investments and causes the decrease in employment and national income. The purpose of this study is examined the relationship between oil prices ana economic growth in Turkey in 2003: Q1-2019: Q4 in the period with quarterly data. Accordingly is used cointegration and causality. According to the findings obtained from the study, a one-way causality was determined from economic growth to oil prices. At the same time, a long-term co-integrated relationship has been found between oil prices and economic growth.
\end{abstract}

Keywords: Oil, oil prices, economic growth.

JEL Classification: Q43, F43, Q32. 


\section{Giriş}

Petrol fiyatlarındaki artış, üretim maliyetlerini arttıracağından dolayı, maliyet enflasyonuna yol açmakta ve bu durum da üretimi ve istihdamı azaltarak ekonomik büyümeyi daraltmaktadır. Çünkü petrol fiyatındaki değişme, ekonomideki bütün ürünlerin fiyatlarına yansıyacaktır. Ayrıca petrol fiyatlarında oluşacak şoklar belirsizlik doğurarak, yatırımları duraksatacaktır.

Dünyada petrol fiyatları belirlenirken 3 tür petrol ele alınmaktadır. Bunlardan ilki Orta Amerika'da çıkan Texas Petrolü (Western Texas Intermediate-WTI), ikincisi Ortadoğu'da çıkarılan Umman petrolü ve 3.sü de, Kuzey Denizinden çıkarılan Brent petrolüdür. Dünyadaki petrol anlaşmalarının yarısından fazlası Brent petrol üzerinden gerçekleştirilmektedir. Diğer bir deyişle, dünyada en yaygın olarak kullanılan petrol türü Brent petroldür ve bu yüzden bu çalışmada Brent petrol fiyatları kullanılmıştır.

Mortgage krizine kadar durağan bir durum izleyen petrol fiyatları, krizle beraber 122 doları görmüş ve sonrasında kademeli olarak düşmüştür. Bu noktada, petrol ihraç eden ülkelerde döviz gelirleri artarken, petrol ithalatçısı ülkelerde imalat sanayinde daralmalar yaşanmıştır.

Bu çalışmanın temel amacı, Türkiye'de 2003:Q1-2019:Q4 dönemlerinde petrol fiyatları ile ekonomik büyüme arasındaki ilişkiyi incelemektir. Bu doğrultuda öncelikle teorik zemin oluşturularak ilgili literatür taramasına yer verilmiş, daha sonra Türkiye'deki petrol fiyatlarının seyrine yer verilmiştir. 2003-2019 döneminde çeyreklik verilerin kullanıldığı bu çalışmada, eşbütünleşme ve nedensellik analizi yapılmıştır.

\section{Teorik Çerçeve ve Literatür Taraması}

Petrol, önemli bir üretim maliyetidir ve petrol fiyatlarındaki artış doğal olarak üretim maliyetlerini de arttırmaktadır. Petrol fiyatları arttıkça, maliyet enflasyonu yaşanacak ve enflasyondaki artış ekonomik büyümeyi azaltacaktır (Gisser ve Goodwin, 1986). Yaşanan maliyet enflasyonu sonucunda, belirsizlik ekonominin geneline yansıyacak ve bu durumda yatırımcılar yatırımlarını ertelemek zorunda kalacaktır. $\mathrm{Bu}$ belirsizlik uzun sürdükçe, yatırımlar olmayacak ve ekonomi daralacaktır (Bernanke, 1983).

Petrol fiyatındaki artış, petrol ihraç eden ülkelerin lehineyken, petrolde dışa bağımlı ülkelerde, girdi maliyetlerinden dolayı maliyet enflasyonu doğuracak ve GSYİH daralacaktır. Ayrıca petrolde dışa bağımlıktan dolayı ödemeler bilançosu da olumsuz etkilenecektir (Özata, 2019). Bununla birlikte, ülkede imalat sanayinde üretim düşecek ve istihdam azalacaktır. $\mathrm{Bu}$ durum da reel GSYİH'yı olumsuz yönde etkilemektedir (Azazi ve Topkaya, 2017).

Hamilton'un 1983'deki çalışması petrol fiyatları ile ekonomik büyüme arasındaki öncü çalışmalardan biridir. Hamilton bu çalışmasında, ABD'de petrol fiyatlarındaki artışın ekonomik büyümeyi negatif etkilediğini göstermiştir (Hamilton, 
1983). Bu kapsamda hazırlanan literatür taramasında, 20 farklı çalışmaya yer verilmiştir ve Tablo 1'de gösterilmiştir.

Tablo 1. Petrol Fiyatları-Ekonomik Büyüme İlişkisi İçin Literatür

\begin{tabular}{|c|c|c|c|}
\hline Yazar (lar) & $\begin{array}{l}\text { Ülke (ler) ve } \\
\text { Dönem }\end{array}$ & Yöntem & Sonuç \\
\hline Lee vd. (1995) & (1949- & VAR analizi & $\begin{array}{ll}\text { Petrol fiyatlarındaki } & \text { şoklar } \\
\text { büyümeyi önemli } & \text { ölçüde } \\
\text { etkilemektedir. } & \end{array}$ \\
\hline $\begin{array}{l}\text { Brown ve } \\
\text { Yücel (1999) }\end{array}$ & $\begin{array}{l}\text { ABD } \quad(1965- \\
1997)\end{array}$ & VAR analizi & $\begin{array}{l}\text { Petrol fiyatlarındaki ani şoklar } \\
\text { reel GSYİH'yı düşürmektedir. }\end{array}$ \\
\hline $\begin{array}{l}\text { Çelik ve Çetin } \\
(2007)\end{array}$ & $\begin{array}{l}\text { Türkiye (1997- } \\
\text { 2006) }\end{array}$ & VAR analizi & $\begin{array}{l}\text { Petrol fiyatlarındaki şoklar, } \\
\text { GSYİH'yı düşürmektedir. }\end{array}$ \\
\hline $\begin{array}{l}\text { Prasad vd. } \\
(2007)\end{array}$ & Fiji (1970-2005) & $\begin{array}{l}\text { Nedensellik } \\
\text { analizi }\end{array}$ & $\begin{array}{l}\text { Petrol fiyatlarından milli gelire } \\
\text { doğru tek taraflı nedensellik } \\
\text { mevcuttur. }\end{array}$ \\
\hline $\begin{array}{l}\text { Anoruo ve } \\
\text { Elike (2009) }\end{array}$ & $\begin{array}{l}6 \text { Afrika ülkesi } \\
(1971-2006)\end{array}$ & $\begin{array}{l}\text { Eşbütünleşme } \\
\text { ve nedensellik }\end{array}$ & $\begin{array}{l}\text { Petrol fiyatlarındaki artış, } \\
\text { ekonomik büyümeyi azaltır. }\end{array}$ \\
\hline $\begin{array}{l}\text { Hanabusa } \\
(2009)\end{array}$ & $\begin{array}{l}\text { Japonya } \quad(2000- \\
2008)\end{array}$ & EGARCH & $\begin{array}{l}\text { Petrol fiyatlarıyla GSYİH } \\
\text { arasında çift taraflı nedensellik } \\
\text { mevcuttur. }\end{array}$ \\
\hline Kumar (2009) & $\begin{array}{l}\text { Hindistan (1975- } \\
\text { 2004) }\end{array}$ & VAR analizi & $\begin{array}{llr}\text { Petrol fiyatlarındaki } & \text { artış, } \\
\text { büyüme hı̈ını ve } & \text { sanayi } \\
\text { üretimini } & & \text { olumsuz } \\
\text { etkilemektedir. } & & \end{array}$ \\
\hline $\begin{array}{l}\text { Al-mulali vd. } \\
(2010)\end{array}$ & $\begin{array}{l}\text { Katar } \quad(1970- \\
2007)\end{array}$ & $\begin{array}{l}\text { Nedensellik } \\
\text { analizi }\end{array}$ & $\begin{array}{l}\text { Petrol fiyatlarındaki artışlar } \\
\text { GSYİH'yı arttırmaktadır. }\end{array}$ \\
\hline $\begin{array}{l}\text { Ghalayini } \\
(2011)\end{array}$ & $\begin{array}{l}\text { G7 (2000-2010), } \\
\text { Hindistan } \quad \text { ve } \\
\text { Rusya } \\
2010), \quad \text { Çin ve } \\
\text { OPEC } \\
2010),\end{array}$ & $\begin{array}{l}\text { Nedensellik } \\
\text { analizi }\end{array}$ & $\begin{array}{l}\text { G7 ülkelerinde petrol } \\
\text { fiyatındaki artış ekonomik } \\
\text { büyümeyi arttırırken; Çin, } \\
\text { Hindistan ve Rusya'da net bir } \\
\text { sonuç yoktur. OPEC için ise } \\
\text { herhangi bir nedensellik tespit } \\
\text { edilememiştir. }\end{array}$ \\
\hline Öksüzler & Türkiye & Nedensellik & $\begin{array}{l}\text { Petrol fiyatlarından büyümeye } \\
\text { doğru tek taraflı nedensellik }\end{array}$ \\
\hline
\end{tabular}




\begin{tabular}{|c|c|c|c|}
\hline İpek (2011) & 2010) & analizi & tespit edilmiştir. \\
\hline $\begin{array}{l}\text { Özsağır } \quad \text { vd. } \\
(2011)\end{array}$ & $\begin{array}{l}\text { Türkiye } \\
\text { 2007) }\end{array}$ & $\begin{array}{l}\text { Eşbütünleşme } \\
\text { ve nedensellik }\end{array}$ & $\begin{array}{l}\text { Petrol fiyatlarındaki } \\
\text { GSYH'yı pozitif } \\
\text { etkilemektedir. }\end{array}$ \\
\hline $\begin{array}{l}\text { Akınc1 } \\
(2012)\end{array}$ & $\begin{array}{l}\text { OPEC ile petrol } \\
\text { ithal eden ülkeler } \\
(1980-2011)\end{array}$ & $\begin{array}{l}\text { Eşbütünleşme } \\
\text { ve nedensellik }\end{array}$ & $\begin{array}{l}\text { OPEC ülkelerinde petrol } \\
\text { fiyatlarındaki artış büyümeyi } \\
\text { arttırırken, ithalatçı ülkelerde } \\
\text { büyüme azalmaktadır. }\end{array}$ \\
\hline Bouzid (2012) & $\begin{array}{l}\text { Tunus } \\
2009)\end{array}$ & $\begin{array}{l}\text { Nedensellik } \\
\text { analizi }\end{array}$ & $\begin{array}{l}\text { Büyümeden petrol fiyatlarına } \\
\text { doğru tek taraflı nedensellik } \\
\text { vardır. }\end{array}$ \\
\hline $\begin{array}{l}\text { Emami } \quad \text { ve } \\
\text { Adibpour } \\
(2012)\end{array}$ & İran (1959-2008) & SVAR analizi & $\begin{array}{lrr}\text { Petrol fiyatları ile } & \text { büyüme } \\
\text { arasında } & \text { negatif } & \text { ilişki } \\
\text { mevcuttur. } & & \end{array}$ \\
\hline $\begin{array}{l}\text { Akınc1 } \\
(2013)\end{array}$ & $\begin{array}{l}\text { OPEC ve petrol } \\
\text { ihracatçısı } \\
\text { ülkeler } \\
\text { 2011) }\end{array}$ & $\begin{array}{l}\text { Eşbütünleşme } \\
\text { ve nedensellik }\end{array}$ & $\begin{array}{l}\text { Petrol fiyatları ile büyüme } \\
\text { arasında pozitif bir ilişki } \\
\text { mevcuttur. }\end{array}$ \\
\hline $\begin{array}{l}\text { Yardımcıŏglu } \\
\text { ve Gülmez } \\
(2013)\end{array}$ & $\begin{array}{l}10 \text { OPEC ülkesi } \\
(1970-2011)\end{array}$ & $\begin{array}{l}\text { Eşbütünleşme } \\
\text { ve nedensellik }\end{array}$ & $\begin{array}{l}\text { Petrol fiyatları ile büyüme } \\
\text { arasında çift taraflı bir } \\
\text { nedensellik tespit edilmiştir. }\end{array}$ \\
\hline $\begin{array}{l}\text { Abimanyu } \\
(2016)\end{array}$ & $\begin{array}{l}\text { Endonezya } \\
(2000-2016)\end{array}$ & $\begin{array}{l}\text { Eşbütünleşme } \\
\text { ve nedensellik }\end{array}$ & $\begin{array}{l}\text { Petrol fiyatları ile büyüme } \\
\text { arasında negatif bir ilişki } \\
\text { mevcuttur. }\end{array}$ \\
\hline $\begin{array}{l}\text { Algan } \\
(2017)\end{array}$ & $\begin{array}{l}\text { Türkiye } \\
\text { 2017) }\end{array}$ & ARDL & $\begin{array}{l}\text { Petrol fiyatlarındaki artış } \\
\text { sanayi üretiminde azalmaya } \\
\text { sebep olmaktadır. }\end{array}$ \\
\hline $\begin{array}{l}\text { Öztürk ve Kılıç } \\
\text { (2018) }\end{array}$ & $\begin{array}{l}26 \text { OECD ülkesi } \\
(1987-2015)\end{array}$ & $\begin{array}{l}\text { Nedensellik } \\
\text { analizi }\end{array}$ & $\begin{array}{l}\text { Petrol fiyatları ile büyüme } \\
\text { arasında çift taraflı nedensellik } \\
\text { mevcuttur. }\end{array}$ \\
\hline $\begin{array}{l}\text { Aktuğ } \\
(2019)\end{array}$ & Irak (1995-2017) & Korelasyon & $\begin{array}{l}\text { Petrol fiyatlarındaki } \\
\text { GSYİH'yı arttırmaktadır. }\end{array}$ \\
\hline
\end{tabular}

Yapılan literatür taramasında, 4 çalışma Türkiye için, 10 çalışma farklı ülkeler için ve 4 çalışmada ülke gruplarını bir arada ele alan panel veri setleri için yapılmıştır. Türkiye için yapılan çalışmalarda Özsağır vd. (2011) çalışmalarında, petrol fiyatlarındaki artış büyümeyi arttırırken; diğer çalışmalarda petrol fiyatlarındaki artış 
ekonomik büyümeyi azaltmaktadır. Diğer çalışmalardan çıkarılacak temel sonuç, petrol ithalatçısı ülkelerde, petrol fiyatlarında meydana gelen bir artışın genelde büyümeyi azalttığı yönündedir.

\section{Türkiye'de Petrol Fiyatlarının Genel Görünümü}

Petrol fiyatlarındaki artış sadece üretim maliyetlerini artırmamakta, aynı zamanda ekonomideki bütün fiyatları etkilemektedir. 1990'lı yılların sonlarında 10 dolara kadar gerileyen petrolün varil fiyatı, daha sonra artma eğilimine girmiş ve ekonomiler için ciddi sorunlar oluşturmuştur. Grafik 1'de 2003-2019 arası dolar bazında Brent petrol fiyatları gösterilmiştir.

\section{Grafik 1: 2003-2019 Dönemi İçin Brent Petrol Fiyatları (\$)}

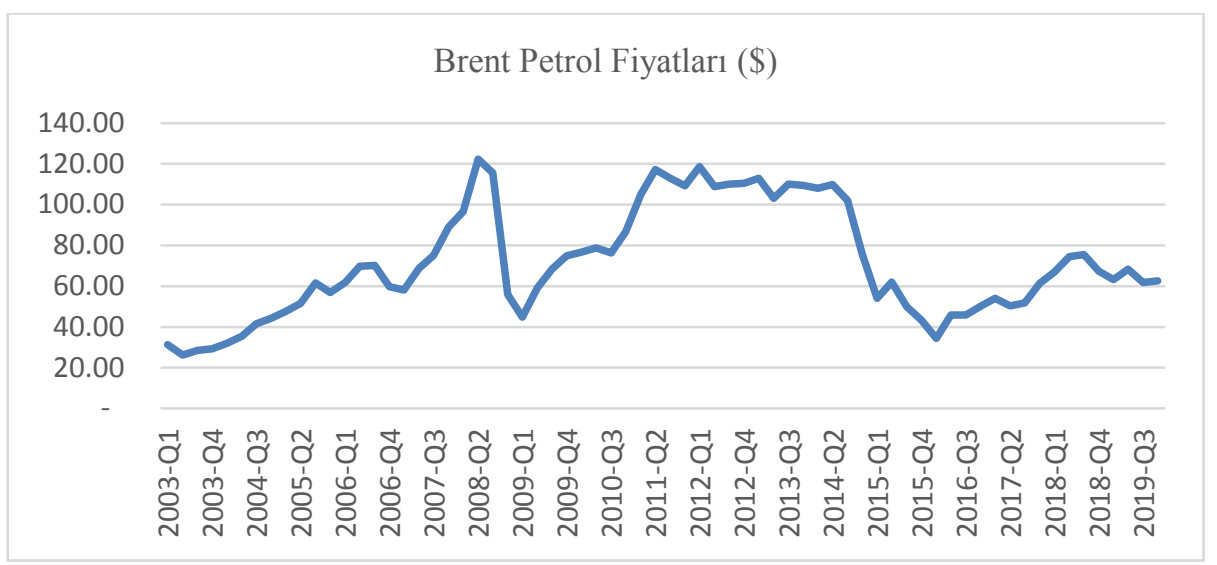

Kaynak: https://fred.stlouisfed.org

Grafik 1'e göre, küresel Brent petrol fiyatları, 2003'den sonra artış göstermiş, Mortagage krizinin etkisiyle 2008'in 2.çeyreğinde 122,24 \$ ile zirveyi görmüştür. 2008'den sonra azalmaya başlasa da 2010'dan sonra tekrar artmış ve 2012'nin ilk çeyreğinde tekrar 118,54 \$ bandına çıkmıştır. Bu tarihten sonra Brent petrol fiyatlarında ciddi düşüşler görülmüş ve Mayıs 2020'de 34,70 \$ bandına gerilemiştir. Petrol fiyatlarının özellikle yaşanan kriz zamanlarında hızlı yükseldiği, sonrasında ise düştüğü görülmektedir.

\section{Ekonometrik Yöntem ve Bulgular}

\subsection{Değişkenler ve Veri Seti}

Bu çalışmada 2003:Q1-2019:Q4 yılları arasında çeyreklik verilerle Türkiye'de Brent petrol fiyatları ile büyüme arasındaki ilişki incelenmiştir. İncelenen öğeler, dolar bazında alınmış ve daha sonra logaritmaları alınarak analize tabi tutulmuştur. Brent 
petrol fiyatları verisi, ABD Merkez Bankası'nın araştırma merkezi olan "fred.stlouisfed.org" adresinden; ekonomik büyüme için GSYİH verisi ise OECD'nin veri tabanı olan "data.oecd.org" adresinden elde edilmiştir.

\subsection{Model ve Yöntem}

Bu çalışmada, (1) no'lu model tahmin edilecektir.

$$
\text { LOGGDPt }=\alpha+\beta 1 \text { LOGPETt }+\varepsilon t
$$

Modelin bağımlı değişkeni ekonomik büyüme olup analizde "LOGGDP" olarak; modelin bağımsız değişkeni ise Brent petrol fiyatları olup analizde "LOGPET" olarak gösterilmiştir.

Serilerin durağanlığının tespiti için ADF birim kök testi yapılmıştır. Seriler birim kök içeriyorsa farkı alınarak durağan hale getirilmiştir. Sonrasında uygun gecikme belirlenerek eşbütünleşme ve nedensellik testi yapılmıştır.

\subsection{Bulgular}

Serilerin durağanlığını belirlemek için Augmented-Dickey Fuller (ADF) birim kök testi yapılmıştır ve sonuçları Tablo 2'de gösterilmiştir

Tablo 2. ADF Birim Kök Testi Sonuçları

\begin{tabular}{|l|l|l|l|}
\hline Değişkenler & Seviye Düzeyi & ADF Test İst. & Olasılık Değ. \\
\hline LOGPET & I $(0)$ & -2.659010 & 0.0869 \\
\hline DLOGPET & I (1) & -3.789490 & 0.0049 \\
\hline LOGGDP & I $(0)$ & -1.085031 & 0.7169 \\
\hline DLOGGDP & I (1) & -3.377194 & 0.0155 \\
\hline
\end{tabular}

Tablo 2'ye göre, petrol fiyatları ve GDP serisi birim kök içermektedir. Bu yüzden 1.farkları alınmıştır. Farkı alınan seriler durağan hale getirilmiştir. İki seri de 1.farkında durağan hale getirilmiştir.

Modelde veri sayısı göz önüne alınarak uygun gecikme uzunluğu belirlenmiş ve Tablo 3'de gösterilmiştir.

Tablo 3. Gecikme Uzunluğu

\begin{tabular}{|l|l|l|l|l|l|}
\hline Lag & LogL & LR & FPE & AIC & SC \\
\hline 0 & -15.08241 & - & 0.005948 & 0.551046 & 0.619663 \\
\hline 1 & 181.7406 & 374.5987 & $1.18 \mathrm{e}-05$ & -5.669052 & $-5.463200^{*}$ \\
\hline 2 & 185.9539 & 7.746943 & $1.18 \mathrm{e}-05$ & -5.675931 & -5.332845 \\
\hline 3 & 191.8224 & $10.41189^{*}$ & $1.11 \mathrm{e}-05^{*}$ & $-5.736206^{*}$ & -5.255885 \\
\hline
\end{tabular}


Tablo 3'e göre, LogL, LR, FPE, AIC ve SC bilgi kriterleri çerçevesinde uygun gecikme uzunluğu 3 olarak belirlenmiştir. Gecikme uzunluğu belirlendikten sonra, uzun dönemli ilişkiyi veren eşbütünleşme analizine geçilmiştir.

Eşbütünleşme analizi, değişkenlerin birbirleriyle ortak hareket edip etmeyeceğini göstermektedir. Zaman serileri seviyesinde durağan değilse ve bu serilerin doğrusal kombinasyonları durağansa bu serilere koentegre ya da eşbütünleşik seriler denilmektedir (Bal, 2012: 14).

Değişkenler arasında uzun dönemli ilişkinin varlığı için Johansen eşbütünleşme testi yapılmış ve Tablo 4'de gösterilmiştir.

\section{Tablo 4. Johansen Eşbütünleşme Testi}

\begin{tabular}{|l|l|l|l|l|}
\hline Trace Testi & Özdeğ. ist. & Trace ist. & \%5 Kr. Değ. & Ola. \\
\hline None & 0.136103 & 14.64703 & 12.32090 & 0.0200 \\
\hline At Most1 & 0.079242 & 5.283740 & 4.129906 & 0.0256 \\
\hline $\begin{array}{l}\text { Maximum } \\
\text { Özd. Testi }\end{array}$ & Özdeğ. & Max-Özd. İst. & \%5 Kr. Değ. & Ola. \\
\hline None & 0.136103 & 9.363287 & 11.22480 & 0.1044 \\
\hline At Most1 & 0.079242 & 5.283740 & 4.129906 & 0.0256 \\
\hline
\end{tabular}

Tablo 4'e göre, $\% 5$ anlamlılık düzeyinde petrol fiyatları ile büyüme arasında eşbütünleşik bir ilişkki mevcuttur. Bu sonuç, petrol fiyatları ile ekonomik büyüme arasında uzun dönemli bir ilişki olduğunu göstermektedir. Eşbütünleşmeden sonra ise nedensellik yapılmış ve Tablo 5'de sonuçları verilmiştir.

Tablo 5. Nedensellik Analizi Sonuçları

\begin{tabular}{|l|l|l|l|}
\hline Bağımlı Değişken: LOGGDP & Olas. \\
\hline Bağımsız Değ. & Chi-sq & Ser.Der. & 0.3877 \\
\hline LOGPET & 3.025250 & 3 & \\
\hline Bağımlı Değişken: LOGPET & \multicolumn{3}{|l|}{} \\
\hline Bağımsız Değ. & Chi-sq & Ser.Der. & Olas. \\
\hline LOGGDP & 9.726949 & 3 & 0.0210 \\
\hline
\end{tabular}

Tablo 5'e göre, ekonomik büyümeden petrol fiyatlarına doğru tek taraflı nedensellik mevcuttur. Petrol fiyatlarından büyümeye doğru ise herhangi bir nedensel ilişki tespit edilememiştir. Nedenselliğin yönü, ekonomik büyümeden petrol fiyatlarına doğru olduğu için, literatürde çoğunlukla bulunan sonuçlardan farklı bir sonuç bulunmuştur. Aynı sonucu bulan farklı çalışmalar da mevcuttur. Yapılan nedensellik analizinde büyümeden petrol fiyatlarına doğru bir nedensellik ortaya çıkmış ve bu durum yapılan literatür taramasında Bouzid (2012) çalışmasıyla aynı sonuçlar vermiştir. 


\section{Sonuç}

Global üretim sürecinde, siyah altın olarak ifade edilen petrol fiyatlarındaki değişmeler, hem Türkiye'yi, hem de dünya ekonomilerini etkilemektedir. Petrol fiyatlarındaki artışlar petrol ihracatçısı ülkelerin milli gelirini arttırırken, Türkiye gibi petrol ithalatçısı ülkelerde büyüme sürecinde daralmalar yaşanmaktadır. Yaşanan bu durum, hem ülkelerdeki üretim sürecini azaltacak, hem de diğer sektörlere aktarılacak kaynaklarda azalmalara yol açacaktır. Bu yönüyle, petrol fiyatları ekonominin genelini etkilemektedir.

Petrol fiyatlarındaki artışlar, Türkiye gibi petrolde dışa bağımlı ülkelerde üretim maliyetlerini arttıracağından dolayı bir maliyet enflasyonu yaşanacaktır. Ayrıca döviz giderleri artarak ödemeler bilançosunda bozulmalar oluşacaktır. Yaşanan bu durum, üretim sürecini azaltarak ülkede istihdamın azalmasına neden olacak ve ekonomik büyüme azalacaktır.

Dünya piyasalarında işlem gören 3 petrol türü bulunsa da, bunlar arasında en yaygın olarak kullanılanı, Brent petrolüdür ve dünya petrol piyasasının yarısından fazlası Brent petrolü üzerinden yapılmaktadır. Bu yüzden bu çalışmada Brent petrol fiyatları kullanılmıştır.

Bu çalışmada, Türkiye'de 2003:Q1-2019:Q4 dönemlerinde petrol fiyatları ile büyüme arasındaki ilişki incelenmiştir. Bu çalışmada bağımsız değişken Brent petrol fiyatları, bağımlı değişken ise ekonomik büyümedir. Çalı̧̧mada öncelikle serilerin durağanlığ 1 sınanmış ve ADF birim kök testi yapılmıştır. Tüm seriler farkında durağan hale geldiği için, uygun gecikme uzunluğu tespit edilerek eşbütünleşme testine geçilmiştir. Yapılan eşbütünleşme testinde seriler arasında uzun dönemli eşbütünleşik ilişki görülmüştür. Daha sonra yapılan nedensellik testiyle, ekonomik büyümeden petrol fiyatlarına doğru tek yönlü nedensellik tespit edilmiştir. Yapılan nedensellik analizinde büyümeden petrol fiyatlarına doğru bir nedensellik ortaya çıkmış ve bu durum yapılan literatür taramasında Bouzid (2012) çalışmasıyla aynı sonuçlar vermiştir.

\section{Kaynakça}

Abimanyu, Y. (2016). Oil price, government revenue, export value, and economic growth: Indonesia's case. Kajian Ekonomi Keuangan, 20(3): 213-230.

Akıncı, M., Aktürk, E. ve Yılmaz, Ö. (2012). Petrol fiyatları ile ekonomik büyüme arasındaki ilişki: Opec ve petrol ithalatçısı ülkeleri için panel veri analizi. Uludağ Üniversitesi İIBF Dergisi, 31(2): 1-17.

Akıncı, M., Aktürk, E. ve Yılmaz, Ö. (2013). Petrol fiyatları ile ekonomik büyüme arasındaki ilişki: Opec ve petrol ithalatçısı ülkeler için zaman serisi analizi. Atatürk Üniversitesi Sosyal Bilimler Enstitüsü Dergisi, 17(1): 349-361. 
Aktuğ, S. S., Dağ, M. ve Star, H. R. (2019). The impact of oil price on economic growth: an investigation on Iraq1 economy. Research Studies Anatolia Journal, 2(6): 273-285.

Algan, N., İşcan, E., Serin, D. ve Kara, D. (2017). Enerji fiyatlarındaki volatilitenin makroekonomik performans üzerine etkisi. International Conference on Eurasian Economies, 2017: 291-300.

Al-mulali, U., Sab, C. ve Normee, C. (2010). The impact of oil shocks on Qatar's GDP. Munich Personal RePEc Archive-MPRA Paper, 27822: 1-25.

Anoruo, E. ve Elike, E. (2009). An empirical investigation into the impact of high oil prices on economic growth of oil-importing African countries. International Journal of Economic Perspectives, 3(2): 121-129.

Azazi, H. ve Topkaya, Ö. (2017). Petrol fiyatlarındaki değişikliğin Türkiye imalat sanayi ve istihdamı üzerindeki etkileri. Selçuk Üniversitesi Sosyal Bilimler Meslek Yüksekokulu Dergisi, 20(1): 14-26.

Bal, O. (2012). Döviz kuru, mevduat faiz oranı, enflasyon ve devlet iç borçlanma senetleri ilişkisi:1994-2008. Akademik Bakış Dergisi, 31:1-20.

Bernanke, B. S. (1983). Irreversibility, uncertainty, and cyclical investment. The Quarterly Journal of Economics, 98(1): 85-106

Bouzid, A. (2012). The relationship of oil prices and economic growthin Tunisia: a vector error correction model analysis. The Romanian Economic Journal, $\mathrm{XV}(43): 3-22$.

Brown, S. P. ve Yücel, M. K. (1999). Oil prices and U.S. aggregate economic activity: a question of neutrality. Economic and Financial Review, Federal Reserve Bank of Dallas, 16-23.

Çelik, T. ve Çetin, A. (2007). Petrol fiyatlarının makroekonomik etkileri: Türkiye ekonomisi için ampirik uygulama. Sosyal Bilimler MYO Dergisi, 10(1-2): 97115 .

Emami, K. ve Adibpour, M. (2012). Oil income shocks and economic growth in Iran. Economic Modelling, 29(5): 1774-1779.

Ghalayini, L. (2011). The interaction between oil price and economic growth. Middle Eastern Finance and Economics 13:127-140.

Gisser, M. ve Goodwin, T. H. (1986). Crude oil and the macroeconomy: tests of some popular notions: a note. Journal of Money, Credit and Banking, 18(1): 95-103. 
Hamilton, J. D. (1983). Oil and the macroeconomy since world war II. Journal of Political Economy, 91(2): 228-248.

Hanabusa, K. (2009). Causality relationship between the price of oil and economic growth in Japan. Energy Policy, 37(5): 1953-1957.

https://fred.stlouisfed.org

Kumar, S. (2009). The macroeconomic effects of oil price shocks: empirical evidence for India. Economics Bulletin, 29(1): 15-37.

Lee, K., Ni, S. ve Ratti, R. A. (1995). Oil shocks and the macroeconomy: the role of price variability. The Energy Journal, 16(4): 39-56.

Öksüzler, O. ve İpek, E. (2011). Dünya petrol fiyatlarıdnaki değişimin büyüme ve enflasyon üzerindeki etkisi: Türkiye örneği. ZKÜ Sosyal Bilimler Dergisi, 7(14): $15-34$.

Özata, E. (2019). Türkiye'de petrol fiyatlarından enflasyona asimetrik ve doğrusal olmayan geçişkenlik. Optimum Ekonomi ve Yönetim Bilimleri Dergisi, 6(1): 1732.

Özsağır, A., Erkan, B., Şentürk, M. ve Kara, O. (2011). Ham petrol fiyatlarındaki volatilitenin gayri safi yurtiçi hasıla büyümesi üzerindeki etkileri: Türkiye örneği. Yönetim ve Ekonomi Dergisi, 18(11): 19-28.

Öztürk, S. ve Kılıç, N. Ö. (2018). Petrol fiyatları ve iktisadi büyüme: Oecd ülkeleri üzerine bir analiz. Ömer Halisdemir Üniversitesi İktisadi ve Idari Bilimler Fakültesi Dergisi, 11(2): 138-149.

Prasad, A., Narayan, P. K. ve Narayan, J. (2007). Exploring the oil price and real gdp nexus for a small Island economy, the Fiji Islands. Energy Policy, 35: 65066513.

Yardımcıoğlu, F. ve Gülmez, A. (2013). OPEC ülkelerinde Hollanda hastalığı: petrol fiyatları ve ekonomik büyüme ilişkisinin ekonometrik bir analizi. Sosyoekonomi, 19(19): 118-140. 